\title{
Factors associated with dietary adherence to the guidelines for prevention and treatment of hypertension among Korean adults with and without hypertension
}

\author{
Jee-Seon Shim ${ }^{*}$ D, Ji Eun Heo and Hyeon Chang Kim
}

\begin{abstract}
Background: Although dietary modification is strongly recommended for prevention and treatment of hypertension, little is known about which factors are associated with adherence to dietary guidelines. We investigated knowledge and attitude, perceived benefits of, barriers to, and self-efficacy of dietary therapy, and identified the factors associated with dietary adherence among adults with and without hypertension.
\end{abstract}

Methods: We collected information on the knowledge/attitudes and perceived benefits of dietary therapy, as well as barriers to and self-efficacy regarding dietary adherence from 497 middle-aged (34-69 years) adults who participated in the follow-up examination of the Cardiovascular and Metabolic Diseases Etiology Center (CMERC) cohort study during December 2018 and February 2019.

Results: Among people without hypertension, 95.5\% (343/359) and 95.8\% (344/359) answered that they would limit sodium intake and consume health diet, respectively, if diagnosed hypertension. However, among people with hypertension, only $79.7 \%(110 / 138)$ and $77.5 \%$ (107/138) reported they were limiting dietary sodium intake and having healthy diet, respectively. Frequency of diet management was not different between normotensive (34.0\%) and hypertensive (35.5\%) groups. Compared to normotensives, hypertensive people were more likely to have lower dietary adherence score, think they need to change their diet, think dietary change impossible, and report lower self-efficacy for following diet guidelines. Dietary management was significantly associated with cardiometabolic risk factors (OR: 1.63) and dietary education (OR: 2.19) among normotensives, while it was associated only with awareness that lifestyle modification is necessary regardless of antihypertensive medication (OR: 6.29) among hypertensive people. Good dietary adherence had significant associations with perceived barriers (OR: 0.71), selfefficacy (OR: 3.71), and dietary education (OR: 1.98) among normotensives; and with perceived barriers (OR: 0.54), self-efficacy (OR: 4.06), and dietary management (OR: 4.16) among hypertensive people.

Conclusions: Many Koreans have relatively low adherence to dietary guidelines for hypertension prevention and treatment. Knowledge, dietary practices, and factors affecting dietary adherence were different between adults with and without hypertension. A targeted approach will be needed to improve blood pressure control of the Korean population.

Keywords: Hypertension, Diet therapy, Self-management, Knowledge, Attitudes, Practice, Therapeutic adherence and compliance, Self-efficacy

\footnotetext{
*Correspondence: shimjs@yuhs.ac

Department of Preventive Medicine, Yonsei University College of Medicine,

Yonsei-ro 50-1, Seodaemun-gu, 03722 Seoul, Republic of Korea
}

(c) The Author(s). 2020 Open Access This article is distributed under the terms of the Creative Commons Attribution 4.0 International License (http://creativecommons.org/licenses/by/4.0/), which permits unrestricted use, distribution, and reproduction in any medium, provided you give appropriate credit to the original author(s) and the source, provide a link to the Creative Commons license, and indicate if changes were made. The Creative Commons Public Domain Dedication waiver (http://creativecommons.org/publicdomain/zero/1.0/) applies to the data made available in this article, unless otherwise stated. 


\section{Background}

Hypertension is a major health burden worldwide [1] The lifetime risk for hypertension for middle-aged and older individuals has been estimated to be as high as $90 \%$ and the prevalence of hypertension has steadily increased with ageing of populations [1, 2]. Uncontrolled blood pressure (BP) has been a major contributor to cardiovascular diseases, stroke, end-stage renal diseases, and the leading cause of death [1, 3, 4]. However, elevated BP is effectively modifiable through antihypertensive medication and lifestyle modifications such as dietary sodium restriction, alcohol moderation, and regular exercise $[5,6]$. Healthy lifestyle can reduce $\mathrm{BP}$ without any harmful side effects, and in addition, can improve overall cardiovascular health $[7,8]$. These benefits of lowered BP have been identified in individuals who have not yet entered the stage where clinical care is required but are still at risk for developing hypertension, as well as those previously diagnosed with hypertension $[6,9,10]$. Thus, lifestyle modification is strongly recommended for hypertensive patients regardless if they are being treated with antihypertensive medications, as well as for normotensive individuals $[5,6]$.

However, guidelines for lifestyle modification are not widely followed [11-13]. Despite the well-known benefits of dietary intervention, compliance with dietary guidelines for hypertension is poorest for health-related behaviors such as non-smoking, alcohol consumption in moderation, and physical activity [13, 14], and unhealthy diet has been reported to be a major barrier to disease management [15]. Several studies have been conducted to gain insight into the knowledge and disease management practices of individuals with hypertension and/or diabetes. However, individuals face unique difficulties depending on their culture, health-care system, food prices, and economic status in the society they live in $[15,16]$. Little is known about which difficulties are prevalent among adults in the South Korean population and whether or not there are gaps in knowledge and dietary practices of individuals with and without hypertension. Thus, in this study, we evaluated knowledge and attitude, perceived benefits of, barriers to, and selfefficacy of dietary therapy, and identified the factors associated with dietary adherence among adults with and without hypertension.

\section{Methods}

\section{Data source and study population}

This study was based on the Cardiovascular and Metabolic Diseases Etiology Research Center (CMERC) cohort study. The design, methods, and rationale of the CMERC cohort study have been reported elsewhere [17]. Briefly, the CMERC cohort was initially designed as a community-based general population cohort study to identify new risk factors and to develop evidence-based prevention strategies for cardiovascular and metabolic diseases in Korea. The cohort comprises communitydwelling middle-aged (age 30-64) adults who were free of cardiovascular diseases. Recruitment and baseline examination had been carried out between 2013 and 2018 at two research clinics, Yonsei University College Medicine in Seoul $(n=4060)$ and Ajou University School of Medicine $(n=4037)$ in Suwon, Korea.

The present analysis used data from a follow-up survey at Yonsei University research clinic between December 2018 and February 2019, since dietary adherence questionnaire was first employed at this survey. Target population for this follow-up survey was 807 adults who were recruited during the first year of enrollment period. During the follow-up period, 2 people died and 18 people withdrew their consent on study participation. Among the remaining 787 participants, a total of 500 participated in the follow-up survey, but three were excluded because of incomplete data. Eventually, 497 adults aged 34 to 69 years were analyzed in this study (Supplementary Fig. S1).

\section{Knowledge of and attitude towards hypertension treatment}

We developed a questionnaire to assess individuals' knowledge and attitudes toward guidelines for hypertension treatment. Questions sought to determine: (1) whether the participant was aware of the health impact of uncontrolled BP and (2) whether they were aware that lifestyle modifications are recommended even in if taking BP-lowering medications. Attitudes regarding selfmanagement guidelines for hypertension including medication, non-smoking, abstinence from alcohol drinking, maintaining optimal body weight, exercise, limiting dietary sodium intake, and consuming a healthy diet, were also investigated [5]. Adults with hypertension were asked to evaluate whether or not they were currently following these guidelines in their daily life. Those without hypertension were asked to answer whether or not they would follow the guidelines if they were to be diagnosed with hypertension.

\section{Dietary self-management, benefits, barriers, and self- efficacy of dietary therapy}

The presence of dietary management was assessed using the question "Are you managing your diet for any special reason?" that is used in the Korea National Health and Nutrition Examination Survey [18]. We surveyed how well participants had followed the individual dietary guidelines for hypertension over the previous month, i.e. reduction in dietary sodium intake, consumption of appropriate amounts of food (not overconsumption), sufficient intake of fruit and vegetables, and a well-balanced 
diet. Each question about dietary practice was referred to the guidelines recommended by the Korean Society of Hypertension (KSH) [5]. Dietary adherence to each guideline was scored based on a scale of 1 (strongly disagree) to 4 (strongly agree). We defined 'good adherence' as a mean score of 3 (75th percentile).

Perceived benefits of and barriers to dietary modification for hypertension were investigated. Participants were asked whether or not they experienced difficulties in preparing meals adherent to the guidelines, the taste of the food, dietary management skills, and changing their dietary habits. Self-efficacy with regard to reducing dietary sodium intake, consuming an appropriate amount of food, having a sufficient intake of fruit and vegetables, and eating a well-balanced diet was assessed by scoring these items from 1 (strongly disagree) to 4 (strongly agree). All information collected was selfreported and our questionnaires relating to diet are presented in Supplementary Fig. S2.

\section{Other variables}

A wide range of information on health status as well as potential factors related to health was collected in the follow-up survey. All participants fasted more than $8 \mathrm{~h}$ prior to examination. Health examination and interviews were conducted by trained research staff according to a predefined study protocol [17].

Socioeconomic status, including education and subjective economic status, medical history including past history of disease, family history of hypertension, frequency of BP measurements over the previous year, awareness of BP values, information on hypertension (only for adults with hypertension) such as age at first diagnosis and current use of medications, and healthrelated behaviors including smoking, drinking, and physical activity were collected by interview.

BP of both arms was measured using an automated oscillometric device (WatchBP office, Microlife, Widnau, Switzerland). Systolic BP (SBP) and diastolic BP (DBP) were repeatedly measured at 1-min intervals after at least 5-min rest in a seated position, and the average of the three measurements was used. More details are provided elsewhere [19]. Hypertension was defined as SBP $\geq$ $140 \mathrm{mmHg}, \mathrm{DBP} \geq 90 \mathrm{mmHg}$, or currently being treated with BP-lowering medications [5].

Weight and height were measured using a stadiometer and a digital scale, respectively, and body mass index (BMI) was calculated. Obesity was defined as BMI $\geq 25.0$ $\mathrm{kg} / \mathrm{m}^{2}$. Diabetes mellitus was defined as either a fasting glucose level $\geq 126 \mathrm{mg} / \mathrm{dL}$ or when participants reported anti-diabetic treatment, such as taking a hypoglycemic agent or insulin. Hypercholesterolemia was defined as serum cholesterol level $\geq 240 \mathrm{mg} / \mathrm{dL}$ or lipid-lowering drug use, hypertriglyceridemia as serum triacylglycerol level $\geq 200 \mathrm{mg} / \mathrm{dL}$ or lipid-lowering drug use, and low HDL-cholesterol as HDL cholesterol level $<40 \mathrm{mg} / \mathrm{dL}$ in men and $<50 \mathrm{mg} / \mathrm{dL}$ in women. If at least one among hypercholesterolemia, hypertriglyceridemia, or low-HDL cholesterol was present, we considered the participant to have dyslipidemia.

\section{Ethical aspects}

This study was approved by the Institutional Review Board (IRB) of Severance Hospital, Yonsei University Health System, Seoul, Korea (4-2013-0661). Written informed consent was obtained from all participants prior to the survey. Study procedures were performed in accordance with the ethical standards of the responsible institutional committee on human experimentation and were in accordance with the Helsinki Declaration (of 1975 as revised in 2008).

\section{Statistical analyses}

Participant characteristics are presented as means \pm SDs or as frequencies (\%). The significance of differences in means and distributions between those with hypertension and those without were assessed using t-tests and chi-square tests. The associations between study variables and self-reported dietary management behavior or dietary adherence to guidelines were analyzed by logistic regression analyses. Sex- and age-adjusted odds ratios (ORs) and multivariable-adjusted ORs and 95\% confidence intervals $(95 \% \mathrm{CIs})$ were calculated. In a multivariate model to explore the factors associated with dietary management behavior, we included sex, age (years), education ( $\geq$ college or $<$ college), cardiometabolic risk (at least one of obesity, diabetes mellitus, or dyslipidemia, or none), family history of hypertension (yes or no), awareness of BP value (aware or not aware), healthy habits (currently a non-smoker, non-drinker, and regular walking, or not), knowledge of the necessity for lifestyle modification regardless of BP-lowering drug treatment (knowledge present or absent), perceived barriers to dietary therapy (number of barriers), self-efficacy regarding following guidelines (mean score ranging from 1 to 4 ), dietary education over the preceding year, and perceived necessity for diet change (yes or no). To explore the factors associated with dietary adherence to hypertension guidelines, the following variables were included in the model: sex, age (years), education ( $\geq$ college or $<$ college), cardiometabolic risk (at least one of obesity, diabetes mellitus, and dyslipidemia, or none), family history of hypertension (yes or no), awareness of BP value (aware or no), healthy habits (currently a non-smoker, non-drinker, and regular walking, or not), knowledge of the necessity for lifestyle modification regardless of BPlowering drug treatment (knowledge present or absent), perceived barriers to dietary therapy (number of 
barriers), self-efficacy regarding following guidelines (mean score ranging from 1 to 4 ), dietary education over the preceding year, and self-reported dietary management behavior (yes or no). We performed logistic regression analyses stratified by adults with and without hypertension. All analyses were performed using the statistical software package SAS (version 9.4; SAS institute, Cary, NC, USA). P-values $<0.05$ were considered statistically significant.

\section{Results}

\section{Demographic and disease-related characteristics of participants}

Among 497 participants, 27.8\% had hypertension $(n=$ 138). Among the hypertensive adults, mean hypertension duration was $8.4 \pm 6.6$ years and more than $90 \%$ of individuals reported that they were taking BP-lowering drugs (Table 1). Hypertensive adults were significantly older, less educated, and had more cardiometabolic risk factors such as obesity, diabetes mellitus, and dyslipidemia than normotensive adults. In addition, more of these participants had a family history of hypertension than nonhypertensive adults. Fortunately, the hypertensive adults measured their BP more frequently than normotensive adults $(P$-value $<0.01)$ and their awareness of their BP value also was higher $(P$-value $<0.01)$. However, there was no difference in lifestyle behaviors at the time of the survey between those with and without hypertension. Experience of dietary education over the preceding year was lower in hypertensive adults than normotensive adults with borderline significance $(P$-value $=0.07)$.

\section{Knowledge of and attitude towards hypertension treatment}

Figure 1 shows the participants' knowledge regarding hypertension treatment and their attitudes towards hypertension control. Almost all adults knew the harmful impact of uncontrolled BP on health, and this did not differ between those with (93.5\%) and without hypertension (95.5\%). Most adults also knew that

Table 1 Demographic and disease-related characteristics of Korean adults with and without hypertension

\begin{tabular}{|c|c|c|c|c|}
\hline & Total $(n=497)$ & Normotensives ( $n=359)$ & Hypertensives ( $n=138$ ) & $P$-value \\
\hline Sex (women) & $346(69.6)$ & $254(70.8)$ & $92(66.7)$ & 0.44 \\
\hline Age (y) & $56.9 \pm 8.5$ & $55.5 \pm 8.8$ & $60.7 \pm 6.2$ & $<0.01$ \\
\hline Education (college or higher) & $195(39.3)$ & $155(43.3)$ & $40(29.0)$ & $<0.01$ \\
\hline Subjective economic status (low) & $81(16.3)$ & $52(14.5)$ & $29(21.0)$ & 0.10 \\
\hline \multicolumn{5}{|l|}{ Cardiometabolic disease status } \\
\hline Obesity $^{a}$ & $155(31.2)$ & $88(24.5)$ & $67(48.6)$ & $<0.01$ \\
\hline Diabetes mellitus ${ }^{b}$ & $46(9.3)$ & $23(6.4)$ & $23(16.7)$ & $<0.01$ \\
\hline Dyslipidemia $^{c}$ & $237(47.7)$ & $143(39.8)$ & $94(68.1)$ & $<0.01$ \\
\hline Family history of hypertension & $229(46.1)$ & $150(41.8)$ & $79(57.3)$ & $<0.01$ \\
\hline Hypertension duration (years) & - & - & $8.4 \pm 6.6$ & - \\
\hline Antihypertensive drug treatment (yes) & - & - & $105(93.8)$ & - \\
\hline \multicolumn{5}{|c|}{ Frequency of BP measurement during the previous 1 year } \\
\hline$\leq 4$ times & $267(53.7)$ & $236(65.7)$ & $31(22.5)$ & \multirow[t]{3}{*}{$<0.01$} \\
\hline $5-12$ times & $161(32.4)$ & $87(24.2)$ & $74(53.6)$ & \\
\hline$>12$ times & $69(13.9)$ & $36(10.0)$ & $33(23.9)$ & \\
\hline Awareness of their own BP value (yes) & $359(72.2)$ & $243(67.7)$ & $116(84.1)$ & $<0.01$ \\
\hline Lifestyle behaviors & $113(22.7)$ & $86(24.0)$ & $27(19.6)$ & 0.35 \\
\hline Current non-smoking & $454(91.4)$ & $328(91.4)$ & $126(91.3)$ & 1.00 \\
\hline Current non-drinking & $191(38.4)$ & $142(39.6)$ & $49(35.5)$ & 0.47 \\
\hline Regular walking ( $\geq 60$ min/day) & $328(66.0)$ & $241(67.1)$ & $87(63.0)$ & 0.45 \\
\hline Dietary education over the past 1 year (yes) & $72(14.5)$ & $58(16.4)$ & $13(9.4)$ & 0.07 \\
\hline
\end{tabular}

Abbreviations: $B P$ blood pressure

Values are presented as $\mathrm{N}(\%)$ or mean \pm SD

${ }^{a}$ Obesity was defined as a body mass index $\geq 25.0 \mathrm{~kg} / \mathrm{m}^{2}$

${ }^{b}$ Diabetes was defined as either a fasting glucose level $\geq 126 \mathrm{mg} / \mathrm{dL}$ or when participants self-reported anti-diabetic treatment, such as taking a hypoglycemic agent or insulin

'Dyslipidemia was defined if any one of hypercholesterolemia (serum cholesterol level $\geq 240 \mathrm{mg} / \mathrm{dL}$ or self-reported lipid-lowering drug use), hypertriglyceridemia (serum triacylglycerol level $\geq 200 \mathrm{mg} / \mathrm{dL}$ or self-reported lipid-lowering drug use), or low HDL-cholesterol (HDL cholesterol level $<40 \mathrm{mg} / \mathrm{dL}$ in $\mathrm{men}$ and $<50 \mathrm{mg} / \mathrm{dL}$ in women, respectively) is present 


\section{(a) Knowledge on hypertension treatment issue}

Uncontrolled BP leads to clinical complications and death. (true)

If treated with BP-lowering medication, lifestyle modification is not necessary. (false)

(b) Self-management attitudes for hypertension control

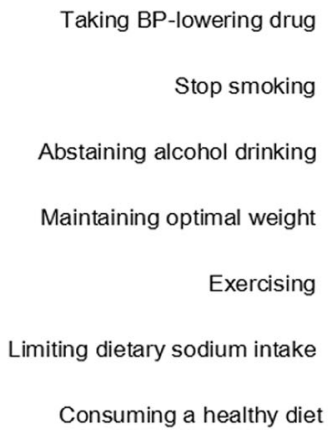

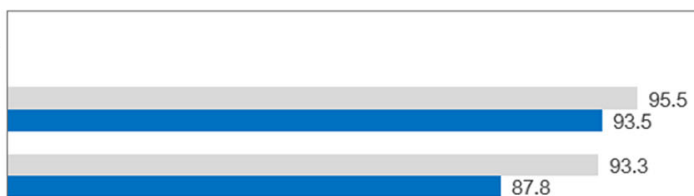

87.8

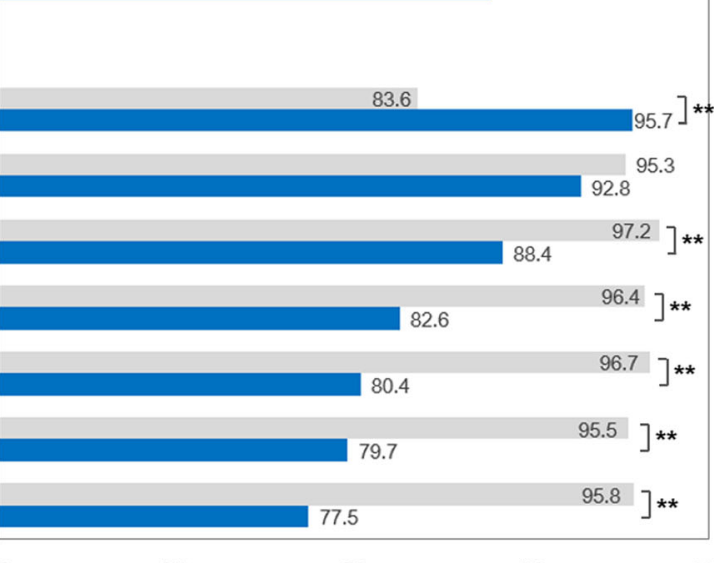

80

90

Adults with hypertension

Fig. 1 Knowledge and attitude on self-management behaviors for hypertension control. ${ }^{* *} P$-value $<0.01$

lifestyle modification was necessary regardless of BPlowering drug treatment, but the proportion of individuals with correct knowledge was slightly different between the two groups. More adults with hypertension (12.2\%) answered that lifestyle modification was not necessary if treated with BP-lowering drug than those without (6.7\%), although this difference did not reach statistical significance $(P$-value $=0.06)$.

The attitude of hypertensive adults was in striking contrast to that of normotensive adults. Nearly all normotensive adults (95.3-97.2\%) responded that they would make an effort to modify their lifestyle (including smoking, drinking, physical activity, diet) and maintain an optimal body weight if they were to be diagnosed with hypertension in the future. Only $83.6 \%$ reported that they would take BP-lowering drugs. However, almost all adults with hypertension (95.7\%) were on a
BP-lowering medication, and only $77.5 \%$ reported that they consumed a healthy diet while $92.8 \%$ said that they had stopped smoking. Diet-related self-management was lower in this group than the normotensive group.

\section{Self-reported dietary management practices and dietary adherence over the past month}

Nearly one in three adults reported that they managed their diet, and the prevalence of self-reported diet management was not different between adults with and without hypertension (Table 2). On the whole, scores for the dietary practice guidelines were not different between the hypertensive and normotensive groups, but hypertensive adults had a significantly lower score for sufficient consumption of fruit and vegetables than normotensive adults $(P$-value $=0.01)$. In addition, the mean of the dietary practice scores for the four

Table 2 Dietary practices over the past month for blood pressure control

\begin{tabular}{|c|c|c|c|c|}
\hline & Total $(n=497)$ & Normotensives $(n=359)$ & Hypertensives $(n=138)$ & $P$-value \\
\hline Self-reported diet management (yes) & $171(34.4)$ & $122(34.0)$ & $49(35.5)$ & 0.83 \\
\hline Dietary practice over the past month (score, range: $1-4$ ) & $2.64 \pm 0.48^{\mathrm{a}}$ & $2.67 \pm 0.46$ & $2.56 \pm 0.54$ & 0.04 \\
\hline I limited my daily sodium diet. & $2.61 \pm 0.74$ & $2.62 \pm 0.73$ & $2.58 \pm 0.78$ & 0.60 \\
\hline I ate proper amount without overeating. & $2.76 \pm 0.65$ & $2.80 \pm 0.61$ & $2.68 \pm 0.74$ & 0.11 \\
\hline I had a diet rich in fruit and vegetable. & $2.68 \pm 0.67$ & $2.72 \pm 0.66$ & $2.55 \pm 0.69$ & 0.01 \\
\hline I had a well-balanced diet. & $2.51 \pm 0.67$ & $2.53 \pm 0.64$ & $2.44 \pm 0.75$ & 0.20 \\
\hline Good adherence (mean dietary practice score of $\geq 3$ ) & $167(33.6)$ & $129(35.9)$ & $38(27.5)$ & 0.09 \\
\hline
\end{tabular}

Values are presented as $\mathrm{N}(\%)$ or mean \pm SD

${ }^{a}$ mean of scores of 4 items (sodium reduction, proper amount of consumption, sufficient consumption of fruit and vegetable, well-balanced meal) 
guidelines was significantly lower in hypertensive adults than normotensive adults $(P$-value $=0.04)$. The prevalence of good adherence (mean dietary practice score of 3 or higher), although slightly lower in hypertensive adults, was not statistically significant between the two groups $(P$-value $=0.09)$.

\section{Perceived benefits of and barriers to following dietary guidelines and self-efficacy}

The majority of adults (78.8\%) stated that they needed to change their current diet, and this proportion was significantly higher in hypertensive adults $(84.8 \%, P$ value $=0.03)($ Fig. 2). Most adults, regardless if they were hypertensive or not, understood the potential benefits of dietary modification on BP control. More than half the participants felt that it was difficult to prepare a meal adherent to the guidelines $(61.6 \%)$ and that BP control diets are tasteless (53.5\%). Thirty-nine percent of participants did not know how to modify their diet and $30.2 \%$ of participants thought that it would be impossible for them to make dietary changes. Difficulty changing old habits was significantly more prevalent in hypertensive adults $(37.7 \%)$ than normotensive adults (27.3\%). Compared with adults without hypertension, those with hypertension had significantly lower self-efficacy scores for the individual guidelines and overall.

\section{Factors associated with dietary management and good adherence}

Potential factors associated with self-reported dietary management are reported in Table 3. For adults without hypertension, dietary management behavior was significantly associated with cardiometabolic risk (OR: 1.63, Pvalue $=0.04)$ and dietary education $(\mathrm{OR}: 2.19, P$-value $=$ 0.01). For hypertensive adults, those who knew that lifestyle modification was necessary even if treated with BP-lowering drugs were 6.29-fold more likely to manage their diet $(P$-value $=0.03)$. Hypertensive individuals who had experienced dietary education over the preceding year tended to manage their diet more than normotensive individuals but this did not reach statistical significance (OR: 2.95, $P$-value $=0.10)$.

\section{(a) Perceived benefits of and barriers to dietary therapy for hypertension (\%)}

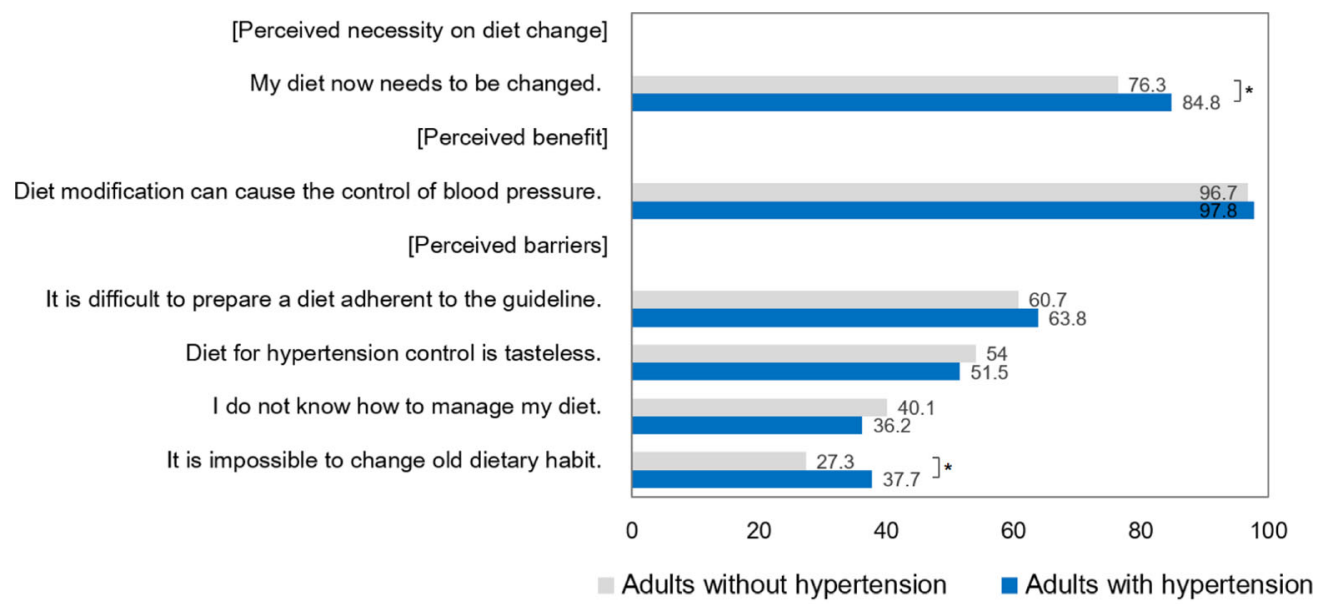

(b) Self-efficacy for following dietary guidelines (score)

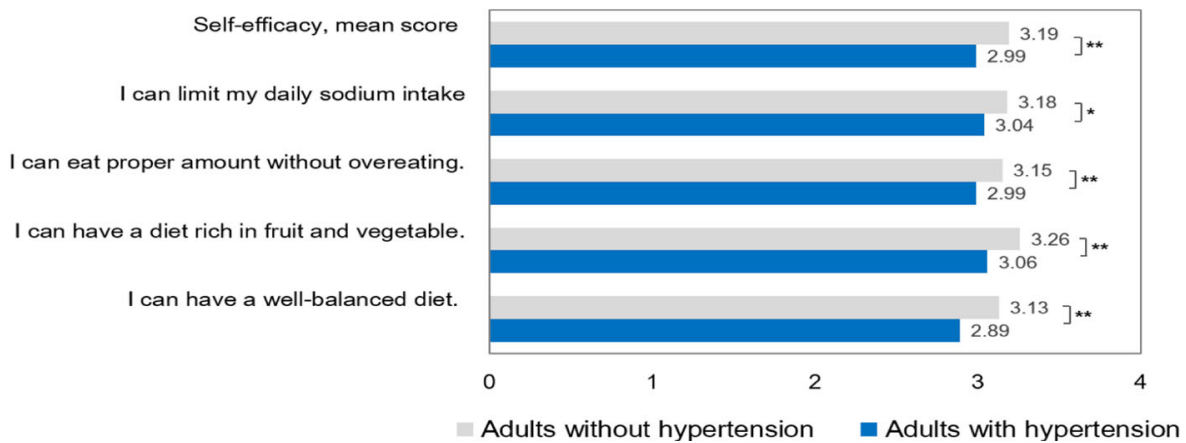

Fig. 2 Perceived benefits of and barriers to dietary therapy for hypertension and self-efficacy for following dietary guidelines. ${ }^{*} P$-value $<0.05,{ }^{* *}$ $P$-value $<0.01$ 
Table 3 Odds ratios (95\% Cl) for self-reported diet management behavior

\begin{tabular}{|c|c|c|c|c|c|}
\hline & & Normotens & $(n=359)$ & Hypertensi & $(n=138)$ \\
\hline & & $\begin{array}{l}\text { Age- sex } \\
\text { adjusted }\end{array}$ & $\begin{array}{l}\text { Fully } \\
\text { adjusted }\end{array}$ & $\begin{array}{l}\text { Age- sex } \\
\text { adjusted }\end{array}$ & $\begin{array}{l}\text { Fully } \\
\text { adjusted }\end{array}$ \\
\hline Sex & (women vs. men) & $\begin{array}{l}1.12(0.69, \\
1.83)\end{array}$ & $\begin{array}{l}0.87(0.50 \\
1.50)\end{array}$ & $\begin{array}{l}1.63(0.76, \\
3.51)\end{array}$ & $\begin{array}{l}1.58(0.66, \\
3.81)\end{array}$ \\
\hline Age & (y) & $\begin{array}{l}1.02(1.00, \\
1.05)\end{array}$ & $\begin{array}{l}1.02(0.99, \\
1.06)\end{array}$ & $\begin{array}{l}0.99 \text { (0.93, } \\
1.04)\end{array}$ & $\begin{array}{l}0.98(0.92, \\
1.05)\end{array}$ \\
\hline Education & $\begin{array}{l}\text { ( } \geq \text { college vs. < } \\
\text { college) }\end{array}$ & $\begin{array}{l}1.31(0.80, \\
2.14)\end{array}$ & $\begin{array}{l}1.02(0.60, \\
1.72)\end{array}$ & $\begin{array}{l}0.68(0.28 \\
1.04)\end{array}$ & $\begin{array}{l}0.61(0.23, \\
1.65)\end{array}$ \\
\hline Cardiometabolic risk & (yes vs. no) & $\begin{array}{l}1.44(0.92 \\
2.25)\end{array}$ & $\begin{array}{l}1.63(1.01 \\
2.63)^{*}\end{array}$ & $\begin{array}{l}1.87(0.69, \\
5.09)\end{array}$ & $\begin{array}{l}1.55(0.51, \\
4.67)\end{array}$ \\
\hline Family history of hypertension & (yes vs. no) & $\begin{array}{l}1.26(0.79 \\
1.98)\end{array}$ & $\begin{array}{l}1.12(0.69 \\
1.82)\end{array}$ & $\begin{array}{l}0.77(0.37 \\
1.60)\end{array}$ & $\begin{array}{l}0.87 \text { (0.40, } \\
1.91)\end{array}$ \\
\hline Awareness of BP value & (know vs. do not) & $\begin{array}{l}0.84(0.52, \\
1.37)\end{array}$ & $\begin{array}{l}0.93(0.56 \\
1.56)\end{array}$ & $\begin{array}{l}0.79(0.30 \\
2.10)\end{array}$ & $\begin{array}{l}0.80(0.28, \\
2.27)\end{array}$ \\
\hline Healthy habit & (yes vs. no) & $\begin{array}{l}1.27(0.76 \\
2.14)\end{array}$ & $\begin{array}{l}1.32(0.77 \\
2.27)\end{array}$ & $\begin{array}{l}0.89(0.35 \\
2.23)\end{array}$ & $\begin{array}{l}1.11(0.41, \\
2.99)\end{array}$ \\
\hline $\begin{array}{l}\text { Knowledge on the necessity for lifestyle modification regardless of } \\
\text { BP-lowering drug use }\end{array}$ & (correct vs. wrong) & $\begin{array}{l}2.93(0.97 \\
8.84)\end{array}$ & $\begin{array}{l}2.60(0.80 \\
8.42)\end{array}$ & $\begin{array}{l}4.71(1.02, \\
21.7)^{*}\end{array}$ & $\begin{array}{l}6.29(1.23, \\
32.3)^{*}\end{array}$ \\
\hline Perceived barriers to dietary therapy & $\begin{array}{l}\text { (the number of } \\
\text { barriers) }\end{array}$ & $\begin{array}{l}0.85(0.71 \\
1.01)\end{array}$ & $\begin{array}{l}0.84(0.68, \\
1.04)\end{array}$ & $\begin{array}{l}1.08(0.82, \\
1.42)\end{array}$ & $\begin{array}{l}1.09(0.78, \\
1.53)\end{array}$ \\
\hline Self-efficacy & (score) & $\begin{array}{l}1.56(0.99 \\
2.50)^{*}\end{array}$ & $\begin{array}{l}1.51(0.93 \\
2.46)\end{array}$ & $\begin{array}{l}1.38(0.68, \\
2.81)\end{array}$ & $\begin{array}{l}1.35(0.60, \\
3.01)\end{array}$ \\
\hline Dietary education & (yes vs. no) & $\begin{array}{l}2.02(1.14 \\
3.58)^{*}\end{array}$ & $\begin{array}{l}2.19(1.20, \\
4.02)^{*}\end{array}$ & $\begin{array}{l}2.31(0.72 \\
7.38)\end{array}$ & $\begin{array}{l}2.95(0.80, \\
10.9)\end{array}$ \\
\hline Perceived necessity for diet change & (yes vs. no) & $\begin{array}{l}1.46(0.85 \\
2.50)\end{array}$ & $\begin{array}{l}1.61(0.90 \\
2.89)\end{array}$ & $\begin{array}{l}1.81(0.61 \\
5.35)\end{array}$ & $\begin{array}{l}1.99(0.61, \\
6.50)\end{array}$ \\
\hline
\end{tabular}

${ }^{*} p$ value $<0.05,{ }^{* *}<0.01$

Cardiometabolic risk was defined if there was at least one of obesity, diabetes mellitus, or dyslipidemia

Healthy habit was defined if it was satisfied with all of current non-smoking, non-drinking, and regular walking

Factors associated with dietary good adherence to hypertension guidelines are presented in Table 4. For hypertensive adults, higher self-efficacy (OR: 4.06, Pvalue $=0.02)$ and the presence of dietary management (OR: 4.16, $P$-value $=0.004)$ and lower perceived barriers to dietary therapy $(\mathrm{OR}: 0.54, P$-value $=0.004)$ were significantly associated with good dietary adherence. Similar associations were found in normotensive adults: self-efficacy (OR: $3.71, P$-value $<0.001)$ and dietary education (OR: $1.98, P$-value $=0.04$ ) had a positive association with good dietary adherence while perceived barriers to dietary therapy (OR: $0.71, P$-value $=0.002$ ) was negatively associated with good dietary adherence.

\section{Discussion}

In this study, we investigated adherence to dietary recommendations for hypertension and identified the factors associated with dietary adherence among community-dwelling adults with and without hypertension. We found that approximately $30 \%$ individuals managed their diet, but the prevalence of diet management was not different between adults with and without hypertension, and dietary adherence score was much lower in those with hypertension than in those without.
Such a low dietary adherence has been reported in previous studies; hypertensive patients showed the best adherence to medication, followed by lifestyle modifications such as drinking and physical activity, and was the poorest for diet [14, 20-22]. In particular, hypertensive patients taking BP-lowering drugs had much unhealthier lifestyles than those who were not taking medications [14, 23].

People with hypertension know that they are supposed to reduce their sodium intake, but often do not follow this dietary guideline [24]. The majority of our participants knew the necessity of lifestyle modification (91.8\%) and understood that diet modification would improve BP control (97.0\%), but the proportions of those who thought that their current diet needed to be changed $(78.7 \%)$ and those who responded managing their diets (34.4\%) were not consistent with the level of knowledge regarding hypertension treatment. In general, the consequence of not taking medication is relatively instant and distinct, whereas the impact of not modifying lifestyle appears to be less immediate and much smaller. For this reason, some people may have no expectation for nonpharmacological treatment [14] or may not feel the need for adopting a healthy lifestyle [20]. There also seems to 
Table 4 Odds ratios (95\% Cl) for good adherence to the guidelines

\begin{tabular}{|c|c|c|c|c|c|}
\hline & & Normotensive & $=359)$ & Hypertensive & $=138)$ \\
\hline & & $\begin{array}{l}\text { Age- sex } \\
\text { adjusted }\end{array}$ & $\begin{array}{l}\text { Fully } \\
\text { adjusted }\end{array}$ & $\begin{array}{l}\text { Age- sex } \\
\text { adjusted }\end{array}$ & $\begin{array}{l}\text { Fully } \\
\text { adjusted }\end{array}$ \\
\hline Sex & (women vs. men) & $\begin{array}{l}1.06 \\
(0.66,1.72)\end{array}$ & $\begin{array}{l}0.81 \\
(0.46,1.43)\end{array}$ & $\begin{array}{l}0.70 \\
(0.32,1.52)\end{array}$ & $\begin{array}{l}0.41 \\
(0.14,1.21)\end{array}$ \\
\hline Age & (y) & $\begin{array}{l}1.02 \\
(0.99,1.05)\end{array}$ & $\begin{array}{l}1.03 \\
(1.00,1.07)\end{array}$ & $\begin{array}{l}1.03 \\
(0.96,1.10)\end{array}$ & $\begin{array}{l}1.05 \\
(0.95,1.15)\end{array}$ \\
\hline Education & $\begin{array}{l}\text { ( } \geq \text { college vs. } \\
<\text { college) }\end{array}$ & $\begin{array}{l}1.51 \\
(0.93,2.46)^{*}\end{array}$ & $\begin{array}{l}1.17 \\
(0.68,2.03)\end{array}$ & $\begin{array}{l}1.98 \\
(0.81,4.83)\end{array}$ & $\begin{array}{l}1.34 \\
(0.45,3.95)\end{array}$ \\
\hline Cardiometabolic risk & (yes vs. no) & $\begin{array}{l}0.63 \\
(0.40,0.97)^{*}\end{array}$ & $\begin{array}{l}0.74 \\
(0.45,1.22)\end{array}$ & $\begin{array}{l}0.65 \\
(0.26,1.64)\end{array}$ & $\begin{array}{l}1.05 \\
(0.31,3.51)\end{array}$ \\
\hline Family history of hypertension & (yes vs. no) & $\begin{array}{l}1.32 \\
(0.84,2.07)\end{array}$ & $\begin{array}{l}1.19 \\
(0.71,1.97)\end{array}$ & $\begin{array}{l}0.99 \\
(0.46,2.16)\end{array}$ & $\begin{array}{l}1.29 \\
(0.50,3.34)\end{array}$ \\
\hline Awareness of $\mathrm{BP}$ value & (know vs. do not) & $\begin{array}{l}0.64 \\
(0.40,1.05)\end{array}$ & $\begin{array}{l}0.72 \\
(0.42,1.24)\end{array}$ & $\begin{array}{l}1.02 \\
(0.37,2.87)\end{array}$ & $\begin{array}{l}1.74 \\
(0.51,5.94)\end{array}$ \\
\hline Healthy habit & (yes vs. no) & $\begin{array}{l}1.15 \\
(0.69,1.93)\end{array}$ & $\begin{array}{l}1.17 \\
(0.66,2.07)\end{array}$ & $\begin{array}{l}1.70 \\
(0.67,4.30)\end{array}$ & $\begin{array}{l}1.61 \\
(0.52,5.04)\end{array}$ \\
\hline $\begin{array}{l}\text { Knowledge on the necessity for lifestyle modification } \\
\text { even when BP-lowering drug use }\end{array}$ & (correct vs. wrong) & $\begin{array}{l}1.85 \\
(0.71,4.83)\end{array}$ & $\begin{array}{l}0.93 \\
(0.29,3.00)\end{array}$ & $\begin{array}{l}0.96 \\
(0.31,2.95)\end{array}$ & $\begin{array}{l}0.27 \\
(0.06,1.14)\end{array}$ \\
\hline Perceived barriers to dietary therapy & $\begin{array}{l}\text { (the number } \\
\text { of barriers) }\end{array}$ & $\begin{array}{l}0.62 \\
(0.51,0.75)^{* *}\end{array}$ & $\begin{array}{l}0.71 \\
(0.57,0.88)^{* *}\end{array}$ & $\begin{array}{l}0.50 \\
(0.35,0.71)^{* *}\end{array}$ & $\begin{array}{l}0.54 \\
(0.36,0.82)^{* *}\end{array}$ \\
\hline Self-efficacy & (score) & $\begin{array}{l}4.25 \\
(2.53,7.13)^{* *}\end{array}$ & $\begin{array}{l}3.71 \\
(2.11,6.51)^{* *}\end{array}$ & $\begin{array}{l}4.73 \\
(1.87,12.0)^{* *}\end{array}$ & $\begin{array}{l}4.06 \\
(1.28,12.9)^{*}\end{array}$ \\
\hline Dietary education & (yes vs. no) & $\begin{array}{l}2.00 \\
(1.13,3.55)^{*}\end{array}$ & $\begin{array}{l}1.98 \\
(1.03,3.80)^{*}\end{array}$ & $\begin{array}{l}1.19 \\
(0.34,4.17)\end{array}$ & $\begin{array}{l}1.05 \\
(0.25,4.48)\end{array}$ \\
\hline Self-reported diet management & (yes vs. no) & $\begin{array}{l}1.96 \\
(1.25,3.08)^{* *}\end{array}$ & $\begin{array}{l}1.61 \\
(0.97,2.68)\end{array}$ & $\begin{array}{l}2.57 \\
(1.17,5.65)^{*}\end{array}$ & $\begin{array}{l}4.16 \\
(1.58,11.0)^{* *}\end{array}$ \\
\hline
\end{tabular}

${ }^{*} p$ value $<0.05,{ }^{* *}<0.01$

Good adherence to the guidelines was defined as $\geq 3$ score of the mean adherence score to 4 guidelines including reduction in dietary sodium intake, consumption in appropriate amount (not overconsuming), sufficient intake of fruit and vegetables, and a well-balanced diet High dietary Cardiometabolic risk was defined if there was at least one of obesity, diabetes mellitus, or dyslipidemia Healthy habit was defined if it was satisfied with all of current non-smoking, non-drinking, and regular walking

be the incorrect belief that that a powerful drug can sufficiently address the harmful effects of unhealthy habits due to a lack of understanding regarding the mechanisms of BP regulation [25]. In our study, not a few participants thought that lifestyle modification is not required if taking medication and this trend was found more in adults with hypertension.

We also found that fewer perceived barriers were significantly associated with good dietary adherence, in both hypertensive and normotensive adults. Qualitative studies have been conducted to understand barriers to changing diet to manage hypertension [15, 16, 23]; one obstacle to dietary compliance is that people have difficulty in changing dietary habits formed over a lifetime [15]. The cost of healthy food, limited availability of appropriate foods, problems in choosing more appropriate foods when eating out, and the cumbersomeness of preparing a low salt diet when cooking meals for family members without hypertension have also been reported to be barriers to dietary change $[15,16,24]$. In our study, one of every three participants thought that it was impossible to change old dietary habits. A considerable number of participants said difficulty in preparing a diet adherent to the hypertension guidelines or did not know how to modify their diet, and more than half mentioned that a hypertension diet was not palatable. Korean sodium consumption has decreased slightly, but is still almost twice the amount recommended by the KSH [26], foods high in sodium, such as instant noodles, Kimchi, soups, and stews are frequently consumed by Koreans [27], and thus adopting a low sodium diet may be a big challenge. However, taste preference is formed as a result of adaptation to what is familiar [28]. Reducing dietary salt intake is initially difficult for most, but once habituated to low salt foods, salty taste preference can be shifted [29]. Effective strategies and consistent efforts to correct misunderstandings as well as lower the perceived barriers to dietary modification and to improve confidence are needed.

To successfully adopt healthy dietary habits, high level of self-efficacy is required. Self-efficacy, the belief in one's ability to organize and take specific actions, has 
been known as a strong predictor of the action required to produce desired outcomes [30]. In our study, higher self-efficacy was positively associated with dietary adherence in both adults with and without hypertension.

Interestingly, our study showed a distinct gap between the attitude of normotensive adults towards hypertension treatment and the hypertensive adults' actual management practices. More than $90 \%$ of adults without hypertension said they would change their lifestyle if they were diagnosed with hypertension in the future. However, among those diagnosed with hypertension, the practice rate of lifestyle modification was much lower. Previous studies have focused on patients with hypertension and/or cardiometabolic diseases [11, 14, 16, 20], thus little is known about the differences between healthy and diseased individuals. It is difficult to explain directly why fewer hypertensive adults followed lifestyle modification guidelines than normotensive individuals. Perhaps hypertensive adults tried to change their unhealthy lifestyles but failed to. The strong motivation of normotensive adults to modify their lifestyle and the relatively low level of self-management practices of hypertensive patients should be considered when physicians and healthcare providers encourage BP control through lifestyle modification.

In addition to aforementioned individuals-related factors (such as knowledge, attitude, and barriers), physician, health care system and society related factors have been identified as obstacles towards following dietary guidelines in daily life. A previous study [31] reported that physicians' perception of hypertension treatment did not correspond to their practice. In the primary care setting, most physicians assessed patients' medication adherence, but provided limited counselling on lifestyle modification [32]. Time constraints and inappropriate compensation were the major obstacles affecting optimal BP control through diet change, and insufficient use of diet services, even in cases where referral to a dietitian was possible, were identified as physician-related barriers $[24,32,33]$. Thus, initiatives to mitigate obstacles to preventive diet counseling and education are needed to reduce the burden caused by elevated BP. Patients with diseases that require self-management skills need to be prioritized and continuity of care needs to be improved. In addition, the social environment may assist patients, and future public campaigns are recommended $[15,16]$.

Our study has several limitations and strengths. First, our subjects do not represent Korean adults. Thus, cares should be taken not to make a generalization error when interpreting the results. Second, the sample size was relatively small. We were unable to analyze adults previously diagnosed with hypertension and those with newly developed hypertension separately. However, our results remained unchanged when we limited the analysis to adults previously diagnosed with hypertension and normotensive individuals. Third, we assessed the presence of dietary management behaviors and of following the dietary guidelines in a self-report manner. In general, information collected by self-report has been known to be less accurate than objective assessment. Although it is well known that self-reported adherence to lifestyle behaviors can be overestimated [34], the low proportion of individuals who managed their diets in this study indicates the need for more aggressive countermeasures. A number of previous studies that have investigated barriers to compliance have been conducted by qualitative interviews such as focus groups $[15,16,24]$, or have focused on a small numbers of individuals affected with hypertension and/or cardiometabolic diseases [14-16, 20]. No information regarding the difficulties encountered by adults or the gaps between individuals with and without hypertension was provided in these previous studies. We observed a distinct difference between normotensive peoples' attitudes towards hypertension treatment and hypertensive adults' current behaviors regarding hypertension treatment.

\section{Conclusions}

Many Korean adults have low adherence to dietary guidelines for the prevention and treatment of hypertension. We found that knowledge, practice, and factors associated with dietary adherence were different between those with and without hypertension. To establish more effective strategies to control blood pressure at a population-level scale, it is important to understand these gaps.

\section{Supplementary information}

Supplementary information accompanies this paper at https://doi.org/10. 1186/s40885-020-00138-y.

Additional file 1: Figure S1. Flow in the study subjects. Figure S2. Questionnaire on dietary adherence, management, benefits, barriers, selfefficacy of dietary therapy

\section{Acknowledgements \\ This study was supported by the Academic Research Fund of the Korean Society of Hypertension (KSH-R-2018-06) and by a grant from the Korea Health Technology R\&D Project through the Korea Health Industry Development Institute (KHIDI), funded by the Ministry of Health \& Welfare, Republic of Korea (grant number HI13C0715).}

\section{Availability of data and material}

The datasets used and/or analyzed during the current study are available from the corresponding author on reasonable request.

\section{Authors' contributions}

SJS designed and conducted the research, analyzed and interpreted data, and wrote the manuscript. JEH was involved in the design of the study and collected data. KHC contributed to the preparation and the revision of the manuscript. All authors read and approved the final manuscript. 


\section{Funding}

This study was supported by the Academic Research Fund of the Korean Society of Hypertension (KSH-R-2018-06) and by a grant from the Korea Health Technology R\&D Project through the Korea Health Industry Development Institute (KHIDI), funded by the Ministry of Health \& Welfare, Republic of Korea (grant number HI13C0715).

\section{Ethics approval and consent to participate}

This study protocol was approved by the Institutional Review Board (IRB) of Severance Hospital, Yonsei University Health System, Seoul, Korea (4-20130661). All participants provided written informed consent.

\section{Consent for publication}

Not applicable.

\section{Competing interests}

The authors declare that they have no competing interests.

\section{Received: 18 December 2019 Accepted: 7 February 2020} Published online: 15 March 2020

\section{References}

1. O'Brien E. The lancet commission on hypertension: addressing the global burden of raised blood pressure on current and future generations. J Clin Hypertens (Greenwich). 2017;19:564-8.

2. Vasan RS, Beiser A, Seshadri S, Larson MG, Kannel WB, D'Agostino RB, Levy D. Residual lifetime risk for developing hypertension in middle-aged women and men: the Framingham heart study. JAMA. 2002;287:1003-10.

3. Lackland DT, Weber MA. Global burden of cardiovascular disease and stroke: hypertension at the Core. Can J Cardiol. 2015;31:569-71.

4. Cushman WC. The burden of uncontrolled hypertension: morbidity and mortality associated with disease progression. J Clin Hypertens (Greenwich). 2003;5:14-22.

5. Lee H-Y, Shin J, Kim G-H, Park S, Ihm S-H, Kim HC, K-i K, Kim JH, Lee JH, Park J-M, Pyun WB, Chae SC. 2018 Korean Society of Hypertension Guidelines for the management of hypertension: part II-diagnosis and treatment of hypertension. Clin Hypertens. 2019;25:20.

6. Whelton PK, Carey RM, Aronow WS, Casey DE Jr, Collins KJ, Dennison Himmelfarb C, DePalma SM, Gidding S, Jamerson KA, Jones DW, MacLaughlin EJ, Muntner P, Ovbiagele B, Smith SC Jr, Spencer CC, Stafford RS, Taler SJ, Thomas RJ, Williams KA Sr, Williamson JD, Wright JT Jr. 2017 ACC/AHA/AAPA/ABC/ACPM/AGS/APhA/ASH/ASPC/NMA/PCNA guideline for the prevention, detection, evaluation, and Management of High Blood Pressure in adults: a report of the American College of Cardiology/American Heart Association task force on clinical practice guidelines. Circulation. 2018; 138:e484-594

7. Dauchet L, Kesse-Guyot E, Czernichow S, Bertrais S, Estaquio C, Péneau S, Vergnaud A-C, Chat-Yung S, Castetbon K, Deschamps V, Brindel P, Hercberg S. Dietary patterns and blood pressure change over 5-y follow-up in the SU. VI.MAX cohort. Am J Clin Nutr. 2007:85:1650-6.

8. Appel LJ. Lifestyle modification as a means to prevent and treat high blood pressure. J Am Soc Nephrol. 2003;14:S99-s102.

9. Olsen MH, Angell SY, Asma S, Boutouyrie P, Burger D, Chirinos JA, Damasceno A, Delles C, Gimenez-Roqueplo AP, Hering D, Lopez-Jaramillo P, Martinez F, Perkovic V, Rietzschel ER, Schillaci G, Schutte AE, Scuteri A, Sharman JE, Wachtell K, Wang JG. A call to action and a lifecourse strategy to address the global burden of raised blood pressure on current and future generations: the lancet commission on hypertension. Lancet. 2016; 388:2665-712

10. Appel LJ, Champagne CM, Harsha DW, Cooper LS, Obarzanek E, Elmer PJ, Stevens VJ, Vollmer WM, Lin PH, Svetkey LP, Stedman SW, Young DR. Effects of comprehensive lifestyle modification on blood pressure control: main results of the PREMIER clinical trial. JAMA. 2003:289:2083-93.

11. Adriouch S, Lelong H, Kesse-Guyot E, Baudry J, Lampure A, Galan P, Hercberg S, Touvier M, Fezeu LK. Compliance with nutritional and lifestyle recommendations in 13,000 patients with a Cardiometabolic disease from the Nutrinet-Sante study. Nutrients. 2017:9(6). https://res.mdpi.com/def502 0086ca360c726691 bee26a48bca598db80cefe2e0cde38e0506b298dd71b1 Odfd09f02496c0d73121bf0962ef8380792f565bb5950f61346e6067bedb612c2 0212d95399fd90a9d8cb2a4e3a8f6ce796a8ace216060169ee7a720fcad39a2 9dda6808949f49356c35b24fe74bd4cf90d21e42fd1cd20b3481a25bdfaa91 7afda110ec887a7ffe4daf1830b3a532855b37ca86f?filename=\&attachment=1 .

12. Kim $Y$, Kong KA. Do hypertensive individuals who are aware of their disease follow lifestyle recommendations better than those who are not aware? PLoS One. 2015;10:e0136858.

13. Park K, Cho S, Bower JK. Changes in adherence to non-pharmacological guidelines for hypertension. PLoS One. 2016;11:e0161712.

14. Kyngas $H$, Lahdenpera $\mathrm{T}$. Compliance of patients with hypertension and associated factors. J Adv Nurs. 1999;29:832-9.

15. Russell BE, Gurrola E, Ndumele CD, Landon BE, O'Malley JA, Keegan T, Ayanian JZ, Hicks LS. Perspectives of non-Hispanic black and Latino patients in Boston's urban community health centers on their experiences with diabetes and hypertension. J Gen Intern Med. 2010;25:504-9.

16. Adams OP, Carter AO. Knowledge, attitudes, practices, and barriers reported by patients receiving diabetes and hypertension primary health care in Barbados: a focus group study. BMC Fam Pract. 2011;12:135.

17. Shim JS, Song BM, Lee JH, Lee SW, Park JH, Choi DP, Lee MH, Ha KH, Kim DJ, Park S, Lee WW, Youm Y, Shin EC, Kim HC. Cohort profile: the cardiovascular and metabolic diseases etiology research center cohort in Korea. Yonsei Med J. 2019;60:804-10.

18. Kweon S, Kim Y, Jang MJ, Kim Y, Kim K, Choi S, Chun C, Khang YH, Oh K. Data resource profile: the Korea National Health and nutrition examination survey (KNHANES). Int J Epidemiol. 2014:43:69-77.

19. Song BM, Kim HC, Shim JS, Lee MH, Choi DP. Inter-arm difference in brachial blood pressure in the general population of Koreans. Korean Circ J. 2016;46:374-83

20. Khan MS, Bawany FI, Mirza A, Hussain M, Khan A, Lashari MN. Frequency and predictors of non-compliance to dietary recommendations among hypertensive patients. J Community Health. 2014;39:732-6.

21. Choi HM, Kim HC, Kang DR. Sex differences in hypertension prevalence and control: analysis of the 2010-2014 Korea National Health and nutrition examination survey. PLoS One. 2017:12:e0178334.

22. Patel P, Ordunez P, DiPette D, Escobar MC, Hassell T, Wyss F, Hennis A, Asma S, Angell S. Improved blood pressure control to reduce cardiovascular disease morbidity and mortality: the standardized hypertension treatment and prevention project. J Clin Hypertens (Greenwich). 2016;18:1284-94.

23. Salomaa V, Vartiainen E, Korhonen HJ, Haukkala A, Tuomilehto J, P P NA. Sydän-ja verisuonitautien vaaratekijät verenpainepotilailla ja muussa väestössä vuosina 1982-1992 (In Finnish.) Cardiovascular risk factors in hypertensive and in population 1982-1992.'. Suom Laakaril. 1994;94:1982-92.

24. DeAndrade S, El Rayess F, Goldman R. Perspectives on hypertension in the New England cape Verdean community. J Racial Ethn Health Disparities. 2018;5:162-9.

25. Ponnusankar S, Surulivelrajan M, Anandamoorthy N, Suresh B. Assessment of impact of medication counseling on patients' medication knowledge and compliance in an outpatient clinic in South India. Patient Educ Couns. 2004; 54:55-60.

26. Korea Centers for Disease Control and Prevention. 2017 Annual report on Korea National Health and Nutrition Examination Survey and Korean Youth Risk Behavior Survey [internet]. Cheongju: Korea Centers for Disease Control and Prevention; 2017 [cited 2019 Dec 18]. Available from: https://knhanes. cdc.go.kr/knhanes/sub04/sub04_03.do?classType=7.

27. Korea Centers for Disease Control and Prevention. The current Korean diet: focusing on the nutritional indices of the fourth National Health Plan [internet]. Cheongju: Kore Centers for Disease Control and Prevention; 2017 [cited 2019 Dec 18]. Available from: https://knhanes.cdc.go.kr/knhanes/ sub04/sub04 04.do.

28. Bobowski N. Shifting human salty taste preference: potential opportunities and challenges in reducing dietary salt intake of Americans. Chemosens Percept. 2015;8:112-6.

29. Bertino M, Beauchamp GK, Engelman K. Increasing dietary salt alters salt taste preference. Physiol Behav. 1986;38:203-13.

30. Martin MY, Person SD, Kratt P, Prayor-Patterson H, Kim Y, Salas M, Pisu M. Relationship of health behavior theories with self-efficacy among insufficiently active hypertensive African-American women. Patient Educ Couns. 2008;72:137-45

31. Wexler R, Elton T, Taylor CA, Pleister A, Feldman D. Physician reported perception in the treatment of high blood pressure does not correspond to practice. BMC Fam Pract. 2009;10:23.

32. Bell RA, Kravitz RL. Physician counseling for hypertension: what do doctors really do? Patient Educ Couns. 2008;72:115-21. 
33. Wynn K, Trudeau JD, Taunton K, Gowans M, Scott I. Nutrition in primary care: current practices, attitudes, and barriers. Can Fam Physician. 2010;56: e109-16.

34. Gee ME, Bienek A, Campbell NR, Bancej CM, Robitaille C, Kaczorowski J, Joffres M, Dai S, Gwadry-Sridar F, Nolan RP. Prevalence of, and barriers to, preventive lifestyle behaviors in hypertension (from a national survey of Canadians with hypertension). Am J Cardiol. 2012;109:570-5.

\section{Publisher's Note}

Springer Nature remains neutral with regard to jurisdictional claims in published maps and institutional affiliations.

Ready to submit your research? Choose BMC and benefit from:

- fast, convenient online submission

- thorough peer review by experienced researchers in your field

- rapid publication on acceptance

- support for research data, including large and complex data types

- gold Open Access which fosters wider collaboration and increased citations

- maximum visibility for your research: over $100 \mathrm{M}$ website views per year

At BMC, research is always in progress.

Learn more biomedcentral.com/submissions 